\title{
How Accurate Are the Consistency Labels Used in Hong Kong? An Objective Study of the Consistency of Thickened Liquids Using International Dysphagia Diet Standardisation Initiative and Consistometric Measurements
}

\author{
Long Yat Wong a Manwa L. $\mathrm{Ng}^{\mathrm{a}}$ Eric T.S. Tong ${ }^{\mathrm{b}}$ \\ a Speech Science Laboratory, Faculty of Education, University of Hong Kong, Hong Kong, China; ${ }^{b}$ Hong Kong Sheng \\ Kung Hui Welfare Council, Hong Kong, China
}

\section{Keywords}

Thickening product · International Dysphagia Diet

Standardisation Initiative · Consistency · Consistometer

\begin{abstract}
Objectives: The present study objectively examined the consistency (thickness) of labels that are used in Hong Kong for the population with dysphagia using an International Dysphagia Diet Standardisation Initiative (IDDSI) flow test and Bostwick consistometric measurements. Methods: Liquids were prepared by thickening water to achieve 4 consistency labels (slightly thick, mildly thick, medium thick, and extra thick) according to manufacturer's instructions, employing 2 types of thickening products that are used in Hong Kong, i.e., starch based and gum based. For each consistency label prepared using each thickening product, the IDDSI flow test and consistometric measurements were obtained and compared. Results: The results showed that the actual thickness of liquids was highly dependent on the type of thickener (starch based vs. gum based) used. Thickened liquids prepared using the starch-based thickener were generally thinner than the actual value at a lower concentration. Conclusion: Though prepared strictly following the manu-
\end{abstract}

karger@karger.com www.karger.com/fpl

Karger!

GOPEN ACCESS
(C) 2021 The Author(s)

Published by S. Karger AG, Basel

This is an Open Access article licensed under the Creative Commons Attribution-NonCommercial-4.0 International License (CC BY-NC) (http://www.karger.com/Services/OpenAccessLicense), applicable to the online version of the article only. Usage and distribution for commercial purposes requires written permission. facturer's instructions, the thickened liquids fail to faithfully correlate with the standardized norms established according to the IDDSI framework and the objective consistometric measurement using a Bostwick consistometer. Therefore, caution must be exercised when administering a thickened diet following the manufacturer's instructions for patients with dysphagia.

(C) 2021 The Author(s)

Published by S. Karger AG, Basel

\section{Introduction}

Dysphagia is a swallowing disorder involving problems in transporting food from the oral cavity to the stomach [1]. With the ageing population, dysphagia is becoming more prevalent. It is estimated to affect about $8 \%$ of the world's population $[2,3]$. A recent study on residential home care services in Hong Kong reported that $62.2 \%$ of residents aged 65 years or older showed various symptoms of dysphagia [unpubl. data]. Serious consequences of dysphagia include aspiration, malnutrition, dehydration, and asphyxiation [2]. As part of dysphagia management, diet modification is commonly carried out to ensure swallowing safety along with adequate nutrition 
and hydration intake. Specifically, for swallowing of liquids, thickeners are mixed with beverages to render a more cohesive bolus with an increased consistency in an attempt to slow down the flow of liquids during the swallow. A slower swallow tends to allow better bolus control and more time for airway closure, thus reducing the risk of aspiration [4-6]. This has been verified using a swallowing model by Stading et al. [7]. In addition, previous reports have also indicated that coherence and consistency of a food bolus can help to increase tactile sensitivity along the swallowing pathway and thus promote a safe swallow $[8,9]$.

A concern regarding the use of thickened liquid is the lack of a clear understanding of terminologies for describing bolus consistency. Different consistency labels and classification systems have been used both across commercial brands and by thickener manufacturers in different countries. For instance, although the International Dysphagia Diet Standardisation Initiative (IDDSI) framework has been adopted as the standard in the USA and the UK, some US thickener manufacturers have adopted a casual and poorly defined labeling system with "nectarlike" and "honey-like" labels for describing liquid consistency, while others from the UK use the labels "syrup," "custard," and "pudding" for different consistency levels. A recent rheological study correlated manufacturer's thickness description with IDDSI guidelines using thickened nonwater beverages [10]. In Hong Kong, local practitioners and commercial thickeners adopt a 5-level system with different terminologies for describing the consistency, i.e., thin, slightly thick, mildly thick, medium thick, and extra thick. However, these labels are not clearly understood or accurately defined by the thickener manufacturer or the scientific community in Hong Kong. Despite the wide acceptance of IDDSI standards worldwide, hospitals and centers for care of the elderly in Hong Kong still rely on these consistency labels when preparing thickened liquids of different thicknesses. With a lack of a standardized working definition of these terminologies of "thickness/consistency," the labels tend to be confusing, and the consistency levels of different standards could not be readily and directly translated across systems $[3,5]$. In fact, Cichero et al. [2] reported that only the US and Japanese standards included descriptions of rheological measures of thickness levels in terms of viscosity, which is the quantity of a liquid's resistance to flow under an applied force [11]. It should be noted that the more recent studies were based on the "recipes" suggested by the thickener manufacturers in the US and/or UK context, i.e., IDDSI standards [12-14]. The lack of a formal definition for thickness/consistency especially in Hong Kong greatly hinders the generalization of research findings on dysphagia around the world. This may have a significant clinical impact as swallowing liquids of an inappropriate thickness may be detrimental to patients with dysphagia.

Moreover, the absence of consistent and well-defined terminologies has led to concerns regarding the quality of thickened liquid preparation. Whether the prepared diet is really of the actual targeted consistency level is questionable. Studies have reported that the consistency labels of commercial products do not always match the actual thickness of liquid, when comparing their viscosity and flow rate to objective references $[15,16]$. Such discrepancies have been found in both ready-to-serve prethickened beverages and liquid thickened using instant thickening agents, even when prepared according to the manufacturer's instructions. Also, studies from Canada, the UK, and the USA have reported great variations in thickness in thickened products of the same consistency labels, both across and within commercial brands [15, 17, 18]. These findings have called into question the quality control by manufacturers of commercial thickening products.

Currently, healthcare professionals generally rely on subjective decisions such as visual inspection and/or stirring in evaluating the consistency of liquids [17, 19]. However, such subjective judgement has been suggested to be unreliable even among experienced speech therapists and nursing staff $[19,20]$. Although sophisticated equipment such as viscometers and rheometers are the gold standard in laboratories for quantification of the thickness/consistency of fluids, they are often inaccessible and impractical to use in clinical settings $[17,21]$.

In the absence of established standards for defining different consistency labels to monitor the quality of thickened liquids, it is questionable whether patients actually receive thickened liquids that are consistent and accurate in relation to that prescribed by speech therapists. Although it is known that the use of thickened liquid can reduce incidents of aspiration in individuals with dysphagia [22], a thicker liquid consistency is associated with the accumulation of pharyngeal residues $[3,5]$, with worsened health outcomes reported in patients who aspirated on very thick liquid [2]. Liquids that are either too thin or too thick could fail to reduce the aspiration risk and promote swallowing safety when they are not thickened to the optimal level that best fits an individual's need. To date, no study has provided objective measurements on the consistency labels commonly used in Hong 
Kong. It is therefore important to understand how good the consistency labels suggested by thickener manufacturers are and to have a standardized protocol to guide the use of thickeners by practitioners in Hong Kong in order to achieve thickness levels that are accurate and appropriate in consistency modification. This study aimed to objectively examine the different consistency labels by using standardized scientific measurements such as the IDDSI framework and consistometry.

\section{IDDSI Framework}

With the aim of developing universal terminologies for diet modification in dysphagia management, Cichero et al. [3] launched the International Dysphagia Diet Standardisation Initiative (IDDSI) framework in 2015. The initiative differentiates a continuum of textures from liquid to solid into 8 levels. Liquids are divided into 5 levels of consistency, i.e., 0 , thin; 1 , slightly thick; 2 , mildly thick; 3 , moderately thick; and 4, extremely thick. Levels 3 and 4 are shared with liquidized food and puree food, respectively. A flow test (IDDSI-FT) using a $10 \mathrm{~mL}$ syringe is used for categorizing liquids into different classes of consistency ranging from level 0 to level 3 , with regards to the remaining volume in the syringe after allowing it to flow under gravity for $10 \mathrm{~s}$ (Table 1). Cichero et al. [2] reported that the test is sensitive in detecting small changes in thickness.

Many studies have examined the clinical use of an IDDSI-FT. Some have reported that the IDDSI-FT is a simple and valid procedure for evaluating swallowing behavior [e.g., 3, 23]. However, some have suggested that other tests such as the line-spread test may be more reliable than IDDSI in evaluating the correct viscosity of a bolus for patients with dysphagia [24].

\section{Consistometry}

Consistometry can be used to quantitatively reflect consistency. It should not be confused with viscosity, which is a measure of the resistance to flow [25]. A Bostwick consistometer is a simple, standardized instrument that can be used to determine the consistency of different materials. It makes use of a single parameter (the distance the fluid traveled) to describe consistency. Although it is more widely used in the food industry for quality control of processed (and thickened) foods such as tomato sauce $[11,26]$, it has also been used in the measurement of modified liquids for dysphagia management $[11,15,17]$. A Bostwick consistometer is calibrated to measure the distance traveled by a liquid sample in $30 \mathrm{~s}$ along a horizontal ruled track [27]. While the IDDSI-FT also measures
Table 1. Classification of liquid consistency by the IDDSI-FT

\begin{tabular}{lc}
\hline Consistency level & IDDSI-FT reference values \\
\hline 0 (thin) & $<1 \mathrm{~mL}$ after $10 \mathrm{~s}$ \\
1 (slightly thick) & $1-4 \mathrm{~mL}$ after $10 \mathrm{~s}$ \\
2 (mildly thick) & $4-8 \mathrm{~mL}$ after $10 \mathrm{~s}$ \\
3 (moderately thick) & $>8 \mathrm{~mL}$ after $10 \mathrm{~s}$ \\
\hline
\end{tabular}

the flow of a liquid under gravity, the Bostwick consistometer is believed to be associated with better sensitivity in discriminating among liquids of thicker consistencies, which is beyond the measurement limits of the IDDSI-FT [15]. That said, other IDDSI methods such as the spoon tilt test and fork and spoon pressure tests can also be used to assess stickiness (adhesiveness) and/or food texture, which is mainly for thicker and solid foods [28].

The current study aimed to provide preliminary yet objective references regarding the consistency labels of liquids prepared using 2 of the most common commercial thickeners available in Hong Kong. All thickened liquids were all prepared in accordance with the manufacturer's instructions into 4 different consistency labels, i.e., slightly thick, mildly thick, medium thick, and extra thick. The consistency labels were examined using the IDDSI framework and consistometry. IDDSI-FT and consistometric measurements were obtained as objective descriptors of liquid consistency.

\section{Methods}

\section{Testing Stimuli}

Two powdered commercial thickeners that are commonly used in hospitals and centers for care of the elderly in Hong Kong were selected. They were a starch-based (ThickenUp ${ }^{\circledR}$; Nestlé Health Science) thickener that contains a modified food starch (maize) and a gum-based (ThickenUp ${ }^{\circledR}$ Clear; Nestlé Health Science) thickener that contains xanthan gum, maltodextrin, and potassium chloride.

\section{Sample Preparation}

Each sample was thickened to the 4 different thicknesses labeled: slightly thick, mild thick, medium thick, and extra thick, following the manufacturer's guidelines for the respective thickener (Table 2). The thickeners were weighed in grams using a household electronic scale $( \pm 0.01 \mathrm{~g})$ instead of per unit scoop as suggested by the thickener manufacturer to ensure reproducible results. As can be seen in Table 2, one scoop was equivalent to $4.5 \mathrm{~g}$ of ThickenUp ${ }^{\circledR}$ and $1.2 \mathrm{~g}$ of ThickenUp ${ }^{\circledR}$ Clear powder. To prepare the thickened liquids, the appropriate amount of water was slowly poured into a beaker containing the corresponding amount of thickener, as instructed by the manufacturer. It was then gently stirred for $1 \mathrm{~min}$ with a fork. Tap water was first boiled and then cooled down to 
Table 2. Recommended dosage of the starch-based and gum-based thickeners by Nestlé Health Science

\begin{tabular}{lcl}
\hline Consistency label & $\begin{array}{l}\text { Resource }{ }^{\circledR} \text { ThickenUp } \\
\text { (starch based) }\end{array}$ & $\begin{array}{l}\text { Resource }^{\circledR} \text { ThickenUp } \\
\text { (gum based) }\end{array}$ \\
\hline Slightly thick & $9 \mathrm{~g}(2$ scoops $) / 300 \mathrm{~mL}$ & $1.2 \mathrm{~g}(1 \mathrm{scoop}) / 100 \mathrm{~mL}$ \\
Mildly thick & $13.5 \mathrm{~g}(3$ scoops $) / 300 \mathrm{~mL}$ & $2.4 \mathrm{~g}(2 \mathrm{scoops}) / 100 \mathrm{~mL}$ \\
Medium thick & $18 \mathrm{~g}(4$ scoops $) / 300 \mathrm{~mL}$ & $3.6 \mathrm{~g}(3$ scoops $) / 100 \mathrm{~mL}$ \\
Extra thick & $22.5 \mathrm{~g}(5$ scoops $) / 300 \mathrm{~mL}$ & $4.8 \mathrm{~g}(4 \mathrm{scoops}) / 100 \mathrm{~mL}$ \\
\hline
\end{tabular}

room temperature $\left(\sim 21^{\circ} \mathrm{C}\right)$ before it was used to mix with different thickening powders. Upon completion of the liquid preparation, a total of 8 samples ( 4 consistency labels $\times 2$ thickener types) were prepared and tested. The mixture was allowed to sit for several minutes in order for the thickening to be completed. Testing took place after the samples were prepared, as it has been found that a prolonged sitting time may change the consistency of the samples.

\section{Measurements}

To obtain an objective measurement of consistency, both the IDDSI-FT and a Bostwick consistometer were used. Three measurements were obtained from each sample in order to minimize measurement errors.

\section{IDDSI Flow Test}

As recommended by the IDDSI [3], a Luer slip tip syringe (reference $302143 ; \mathrm{BD}^{\mathrm{TM}}$, Belgium) with a measurement capacity of 10 $\mathrm{mL}$ was used. To obtain each measurement, $10 \mathrm{~mL}$ of thickened liquid were placed into an empty syringe, with a finger covering the nozzle to avoid leakage. The nozzle was then released to allow the flow of liquid for $10 \mathrm{~s}$. It was covered again at exactly $10 \mathrm{~s}$ and the volume of liquid remaining in the syringe was recorded.

\section{Bostwick Consistometry}

A standard Bostwick consistometer (CSC Scientific Company, Inc.) was used to quantify liquid consistency (Fig. 1). The consistometer is made of stainless steel and contains 2 compartments. The first compartment is the reservoir, which has the dimensions $5 \mathrm{~cm}$ (width) $\times 5 \mathrm{~cm}$ (length) $\times 3.8 \mathrm{~cm}$ (height). It is fitted with a spring trap door on one end of the consistometer. The second compartment is a long horizontal trough that is $24 \mathrm{~cm}$ long and $5 \mathrm{~cm}$ wide, with ruled markings of $0.5-\mathrm{cm}$ intervals on the floor of the trough (Fig. 1).

For each measurement, thickened liquid was poured into the reservoir, slightly overfilled, and then leveled with a spatula to hold a sample of exactly $75 \mathrm{~mL}$. The spring gate was then released to allow fluid to flow along the horizontal trough for $30 \mathrm{~s}$. The consistometric measure was obtained from the distance traveled by the thickened liquid, which was calculated by averaging the farthest distance indicated at the center and the shortest distance at the edge. Such distance measurements were recorded to the nearest 0.5 $\mathrm{cm}$. After each measurement, the consistometer was washed thoroughly by rinsing under running water for at least $1 \mathrm{~min}$ and dried completely with a paper towel.

\section{Statistical Analysis}

To assess for possible significant main effects for thickener type and consistency label in the IDDSI-FT and consistometric mea-

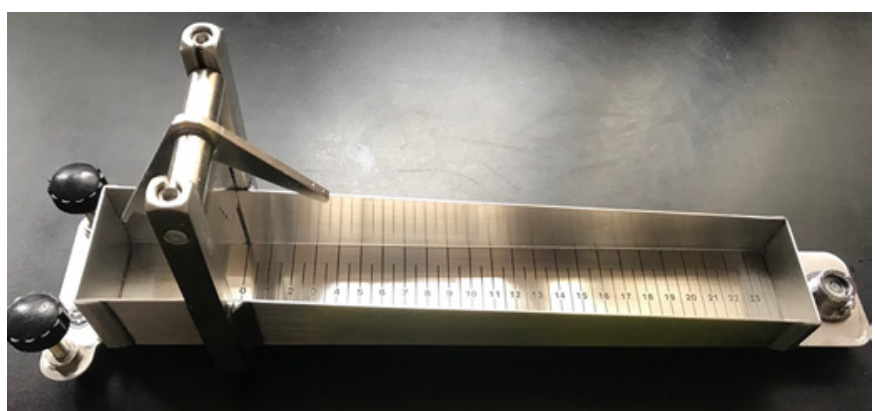

Fig. 1. Bostwick consistometer.

sures, two $2 \times 4$ (thicker type $\times$ consistency label) two-way analysis of variance (ANOVA) were carried out, i.e., one for IDDSI-FT measures and one for consistometric measures. They were followed by subsequent post hoc multiple comparisons when necessary.

\section{Results}

The average IDDSI-FT measures (in $\mathrm{mL}$ ) and Bostwick consistometric measures (in $\mathrm{cm}$ ) associated with the 4 consistency labels prepared using both starch-based and gum-based thickeners are shown in Table 3. For easier comparison, the values associated with starch-based and gum-based thickeners are depicted in Figures 2 and 3 , respectively. Results from the two-way ANOVA indicated significant interaction effects in both IDDSI-FT and consistometric measurements between thickening products (starch based vs. gum based) and consistency labels $(p<0.001)$. Independent-samples $t$ tests and oneway ANOVA were then implemented to investigate the simple main effects of thickening product and consistency level, respectively.

\section{Starch-Based vs. Gum-Based}

Significant differences in thickness were observed between thickening products at each level of consistency for 
Table 3. IDDSI-FT measurements and consistometric measurements associated with different consistency labels prepared using starch-based and gum-based thickeners

\begin{tabular}{llll}
\hline Consistency label & Thickener type & $\begin{array}{l}\text { IDDSI-FT measurement, } \\
\mathrm{mL}\end{array}$ & $\begin{array}{l}\text { Consistometric measurement, } \\
\mathrm{cm}\end{array}$ \\
\hline Slightly thick & $\begin{array}{l}\text { Starch based } \\
\text { Gum based }\end{array}$ & $\begin{array}{l}0.00(0.000)^{\mathrm{a}} \\
7.00(0.200)\end{array}$ & $\begin{array}{l}24.00(0.000)^{\mathrm{b}} \\
16.17(0.764)\end{array}$ \\
\hline Mildly thick & Starch based & $4.60(0.400)$ & $16.83(0.577)$ \\
& Gum based & $9.07(0.115)$ & $11.17(0.289)$ \\
\hline Moderately thick & Starch based & $9.07(0.115)$ & $8.67(0.289)$ \\
& Gum based & $9.80(0.200)$ & $9.00(0.000)$ \\
\hline Extra thick & Starch based & $10.00(0.000)^{\mathrm{b}}$ & $3.33(0.577)$ \\
& Gum based & $10.00(0.000)^{\mathrm{b}}$ & $7.17(0.289)$
\end{tabular}

Values are presented as means (SD). ${ }^{a}$ Measurements with a floor effect. ${ }^{\mathrm{b}}$ Measurements with a ceiling effect.

Fig. 2. Mean IDDSI-FT measurements (in $\mathrm{mL}$ ) associated with different consistency labels prepared using starch-based and gum-based thickeners.

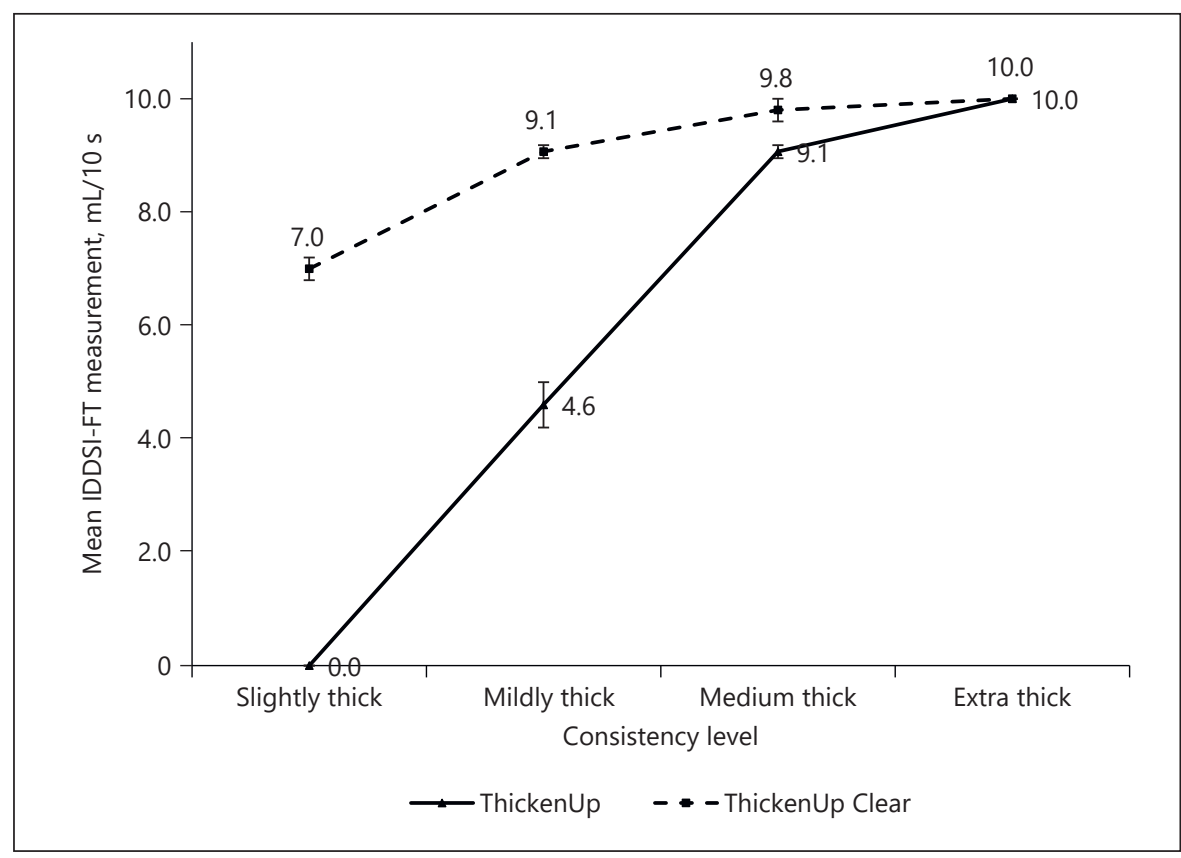

both IDDSI-FT and consistometric measurements, except for the consistency level "medium thick," measured using the Bostwick consistometer $(t[4]=-2, p=0.116>$ 0.05). IDDSI-FT measurements of "extra thick" were not compared due to a floor effect in measurement. Consistometric measures indicated that consistency labels prepared using the starch-based thickener were significantly thinner than those prepared using the gum-based thickener for "slightly thick" $[t(4)=17.76, p<0.001]$ and "mildly thick" $[t(4)=15.21, p<0.001]$. Similar findings were observed for IDDSI-FT measures for "slightly thick" $[t(4)=-60.62, p<0.001]$, "mildly thick" $[t(4)=-18.58, p$ $<0.001]$, and "medium thick" $[t(4)=-5.5, p=0.005<$ $0.01]$. Consistometric measures associated with "extra thick," prepared using the starch-based thickener, were significantly thicker than those prepared using the gumbased thickener $[t(4)=-10.29, p=0.001<0.01]$.

\section{Among Different Consistency Labels}

For both IDDSI-FT and consistometric measures, significant main effects for consistency label were observed for both starch-based and gum-based thickeners. For 
Fig. 3. Mean consistometric measurements (in $\mathrm{cm}$ ) associated with different consistency labels prepared using starch-based and gum-based thickeners.

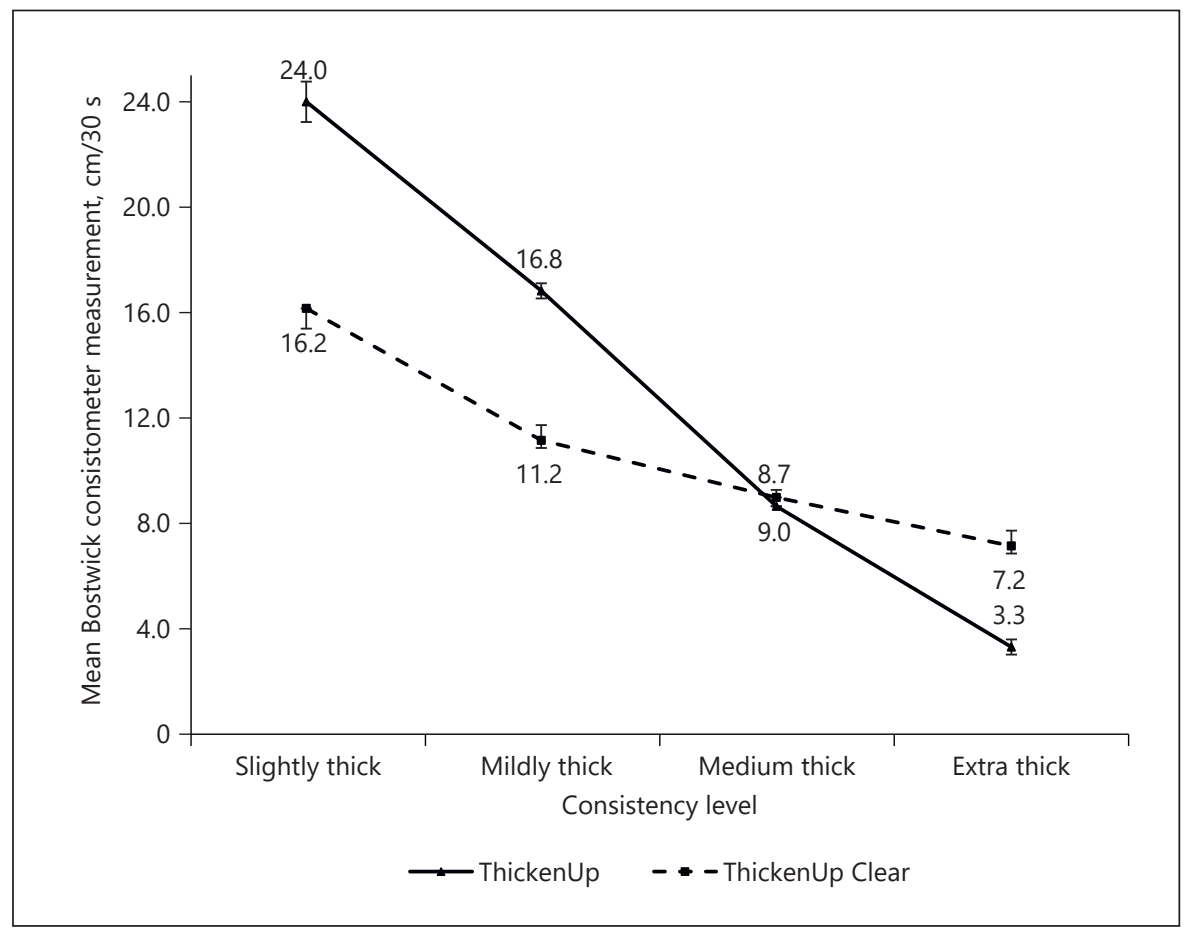

consistometric measures, there were significant differences between the consistency labels of liquids prepared with starch-based thickeners $[F(3,8)=1,321.30, p<$ $0.001]$ and those prepared with gum-based thickeners $[F(3,8)=241.89, p<0.001]$. The same was observed in IDDSI-FT measures for starch-based $[F(3,8)=1,461.62$, $p<0.001]$ and gum-based $[F(3,8)=241.71, p<0.001]$ thickeners. Subsequent post hoc multiple comparisons revealed that, for both thickening types, the thickness associated with any consistency label was significantly different from the other 3 ( $p<0.01)$, except between "medium thick" and "extra thick," prepared using a starchbased thickener measured using the IDDSI-FT $(p>0.05)$ (the presence of a measurement floor should be noted).

\section{Mapping between Consistency Labels and IDDSI Consistency Classifications}

In addition, the consistency of liquids of different consistency labels prepared using starch-based and gumbased thickeners following the manufacturer's instructions was matched with IDDSI levels. Liquids of the consistency label "slightly thick" prepared using starch-based and gum-based thickeners were classified as IDDSI level 0 (thin) and level 2 (mildly thick), respectively. Liquids of the mildly thick consistency label prepared using starchbased and gum-based thickeners showed a consistency at the lower end of IDDSI level 2 (mildly thick) and IDDSI level 3 (moderately thick), respectively. For liquids of the consistency label "medium thick," prepared using starchbased and gum-based thickeners, both consistencies were classified as IDDSI level 3 (moderately thick). Finally, liquids of the consistency label "extra thick" were not used for comparisons as a measurement floor was observed for both products; no flow was observed during the IDDSIFT.

\section{Discussion}

The lack of standardization in consistency classification is a major concern surrounding the use of thickened liquids for patients with dysphagia in Hong Kong. The present study objectively and quantitatively examined the consistency of liquids according to the labels "slightly thick," "mildly thick," "medium thick," and "extra thick," prepared using starch-based and gum-based thickeners strictly according to the manufacturer's instructions.

As expected, liquids prescribed using the commercial thickening products were in ascending order of thickness as suggested by their labels, i.e., "slightly thick" was the thinnest whereas "extra thick" was the thickest for both starch-based and gum-based thickeners when examined using both IDDSI-FT and consistometric measurements. However, variations in the actual thickness (as indicated 
Table 4. Recommended dosage fo Nestlé Health Science starch-based and gum-based thickeners to match the IDDSI framework

\begin{tabular}{|c|c|c|}
\hline IDDSI consistency & $\begin{array}{l}\text { Resource }^{\circledR} \text { ThickenUp }{ }^{\circledR} \\
\text { (starch based) }\end{array}$ & $\begin{array}{l}\text { Resource }^{\circledR} \text { ThickenUp }{ }^{\circledR} \text { Clear } \\
\text { (gum based) }\end{array}$ \\
\hline Level 1 (slightly thick) & $10.125 \mathrm{~g}(2.25 \mathrm{scoops}) / 300 \mathrm{~mL}$ & $0.6 \mathrm{~g}(0.5 \mathrm{scoops}) / 100 \mathrm{~mL}$ \\
\hline Level 2 (mildly thick) & $13.5 \mathrm{~g}$ (3 scoops)/300 mL & $1.2 \mathrm{~g}(1 \mathrm{scoop}) / 100 \mathrm{~mL}$ \\
\hline Level 3 (moderately thick) & $16.875 \mathrm{~g}(3.75$ scoops $) / 300 \mathrm{~mL}$ & $2.4 \mathrm{~g}(2 \mathrm{scoops}) / 100 \mathrm{~mL}$ \\
\hline Level 4 (extremely thick) & $20.25 \mathrm{~g}$ (4.5 scoops)/300 mL & $3.6 \mathrm{~g}$ (3 scoops)/100 mL \\
\hline
\end{tabular}

The original recommended dosage was provided to guide the preparation of $200-\mathrm{mL}$ liquids. The formulae were recalculated for a better comparison with the guideline provided for use in Hong Kong.

by IDDSI-FT and consistometric measures) were observed between thickened liquids prepared using the 2 types of thickeners, even when strictly following the instructions provided by the thickener manufacturer. The starch-based thickener exhibited a wider range of thickness variation across the 4 consistency labels. In addition, significant differences in thickness were observed between liquids prepared using starch-based and gumbased thickeners for all 4 consistency labels, with liquids prepared using the starch-based thickener being thinner than those using the gum-based thickener at a lower concentration, even though both thickening products were provided by the same manufacturer. This suggests that the desired thickness level of liquids prescribed by speech therapists might not be accurately achieved when a different type of thickener is used, even when drinks are thickened to the same consistency label following the manufacturer's instructions. If speech therapists rely only on the instructions of the thickener manufacturer in preparing a modified diet, this may result in patients with dysphagia taking liquids of an incorrect thickness.

Variations in thickness could originate from the ingredients of thickeners, as modified starch (ThickenUp ${ }^{\circledR}$ ) and xanthan gum (ThickenUp ${ }^{\circledR}$ Clear) possess distinct rheological properties and likely interact differently with liquids $[29,30]$. Currently, the industry of thickening products mainly relies on viscosity measurements for product standardization [15]. While within-brand variations might reflect a lack of quality control by the manufacturers during thickener production, the flow of thickened liquids observed in the current study could have been influenced by a number of factors other than viscosity, such as surface tension, fluid density, and yield stress $[31,32]$. Between the 2 thickener types, xanthan gum is characterized by yield stress, which can be understood as the minimum stress that must be applied to start the flow
[33], and it directly determines retention of materials on the wall of passageway [34]. This may explain why the liquids prepared using the gum-based thickener flowed more slowly in either test and were found to be thicker than their respective consistency labels on both measurements. Regardless of the reason, the discrepancy between consistency labels and the actual consistency measured using the IDDSI-FT and the consistometer indicated the inadequacy of manufacturers' labels in reflecting the actual flow of thickened fluids.

The aim of theis study was to examine the compatibility between the consistency labels of liquids prepared using starch- and gum-based thickeners commonly used in Hong Kong and the actual consistency revealed by IDDSI-FT and Bostwick consistometer. The present IDDSI-FT results suggest that the consistency labels of liquids prepared using commercial thickeners in Hong Kong do not conform to the corresponding IDDSI levels, with difficulties heightened by a lack of local standardization on consistency modification (Fig. 1,2). Such discrepancy in consistency labels and the actual consistency levels advocated by the IDDSI has been confirmed and acknowledged by the manufacturer $[35,36]$, after which a menu of recommended dosages for thickeners to match the various IDDSI consistency levels (Table 4) was set up for both starch-based (ThickenUp ${ }^{\circledR}$ ) and gum-based (ThickenUp ${ }^{\circledR}$ Clear) thickeners sold in the UK. In fact, despite having established national standards on consistency modification, Australia, the UK, and the USA have formally adopted the IDDSI framework [37-39]. At present, the Chinese (Hong Kong) translation of the framework was undergoing peer review [40]. However, concerns regarding IDDSI consistency levels have been raised. In the present study, liquids with the consistency labels "mildly thick" and "medium thick," prepared using the gum-based thickener, 
were both classified as the same level with IDDSI-FT. Côté et al. [15] also demonstrated that fluids of distinct flows matched with the IDDSI reference values because of the broad boundary points. Further research on the boundaries of clinical importance across consistency levels may be needed to support local implementation of the IDDSI framework.

It should be noted that the 2 objective measurements employed in the present study highly correlated with each other. Both IDDSI-FT and consistometric measurements were able to consistently discriminate between the 4 different thicknesses, yet they do not seem to be equally sensitive in measuring consistency across levels. The present results indicated that, unlike IDDSI-FT measures, the Bostwick consistometer appeared to be more sensitive in discriminating samples of a higher consistency, as indicated by the presence of floor and ceiling measurement effects in IDDSI-FT measurement, but not for the consistometer. However, the IDDSI-FT can easily be carried out by any stakeholder (the clinician, the caregiver, or the the patient him-/herself) and thus liquids could be tested at the point of service, regardless of the thickener and dosage used. Nevertheless, both methods are suggested to be reliable and can yield objective measures that are easy to use in clinical settings. The establishment of reference values for the Bostwick consistometer in future studies could help to provide another standardized measure for categorization of liquids of a thicker consistency. In addition, other IDDSI measurement methods such as the spoon tilt test and the fork pressure test could also be explored.

\section{Conclusion}

The present study revealed that both IDDSI-FT and consistometric measurements are useful for objective and quantitative evaluation of liquid consistency. By comparing the IDDSI-FT and consistometric measures associated with the 4 consistency labels prepared according to the manufacturer's instructions, it was shown that consis- tency labels do not conform to the established standards advocated by the IDDSI framework. Differences were also observed between starch-based and gum-based thickeners. These findings suggest that, in Hong Kong, the consistency levels may not match the IDDSI standards, and it is recommended that thickened liquids be prepared according to the IDDSI-FT instead of merely relying on the manufacturer's instructions, at least for ThickenUp ${ }^{\circledR}$ Clear and Resource ThickenUp ${ }^{\circledR}$ Clear.

\section{Statement of Ethics}

An ethics statement was not required for this study type, as no human or animal subjects or materials were used.

\section{Conflict of Interest Statement}

The corresponding author of this article is currently an associate editor of Folia Phoniatrica et Logopaedica. All of the authors have no conflict of interests to declare.

\section{Funding Statement}

The authors received no financial support for the research, authorship, and/or publication of this article.

\section{Author Contributions}

L.Y. Wong was responsible for data collection and preliminary preparation of this paper. M.L. Ng oversaw the entire project, ranging from the establishment of the research topic, through the literature review and data analysis, to the preparation of this paper. E.T.S. Tong contributed to the research topic and was involved in the preparation of this paper.

\section{Data Availability}

All data generated and analyzed during this study are included in the article. Further enquires can be directed to the corresponding author.

\section{References}

1 Logemann J. Evaluation and treatment of swallowing disorders. 2nd ed. Texas: PROED; 1998. https://doi.org/10.1097/00020840199812000-00008.

2 Cichero JA, Steele C, Duivestein J, Clavé P, Chen J, Kayashita J, et al. The need for international terminology and definitions for texture-modified foods and thickened liquids used in dysphagia management: foundations of a global initiative. Curr Phys Med Rehabil Rep. 2013 Aug;1(4):28091.

3 Cichero JA, Lam P, Steele CM, Hanson B, Chen J, Dantas RO, et al. Development of international terminology and definitions for texture-modified foods and thickened fluids used in dysphagia management: the IDDSI Framework. Dysphagia. 2017 Apr;32(2):293314.

4 Garcia JM, Chambers E 4th, Matta Z, Clark M. Viscosity measurements of nectar- and honey-thick liquids: product, liquid, and time comparisons. Dysphagia. 2005;20(4):325-35. 
5 Steele CM, Alsanei WA, Ayanikalath S, Barbon CE, Chen J, Cichero JA, et al. The influence of food texture and liquid consistency modification on swallowing physiology and function: a systematic review. Dysphagia. $2015 \mathrm{Feb} ; 30(1): 2-26$.

6 Vose A, Nonnenmacher J, Singer ML, González-Fernández M. Dysphagia management in acute and sub-acute stroke. Curr Phys Med Rehabil Rep. 2014 Dec;2(4):197-206.

7 Stading M, Waqas MQ, Holmberg F, Wiklund J, Kotze R, Ekberg O. A device that models human swallowing. Dysphagia. 2019 Oct;34(5):615-26.

8 Loret C. Using sensory properties of food to trigger swallowing: a review. Crit Rev Food Sci Nutr. 2015;55(1):140-5.

9 Machado AS, Lenz D, de Souza RD, Eugênio RM, de Andrade TU, Pereira TC, et al. Lack of standardization in commercial thickeners used in the management of dysphagia. Ann Nutr Metab. 2019;75(4):246-51.

10 Kwong E, Tse SK. Application of a manufacturer's guideline and an IDDSI-driven guideline to thickening of some non-water beverages: A rheological study. Dysphagia. 2020;36;270-80.

11 Germain I, Dufresne T, Ramaswamy HS. Rheological characterization of thickened beverages used in the treatment of dysphagia. J Food Eng. 2006;73(1):64-74.

12 Barbon CE, Steele CM. Thickened liquids for dysphagia management: a current review of the measurement of liquid flow. Curr Phys Med Rehabil Rep. 2018 Dec;6(4):220-6.

13 Barbon CE, Steele CM. Characterizing the flow of thickened barium and non-barium liquid recipes using the IDDSI flow test. Dysphagia. 2019 Feb;34(1):73-9.

14 Steele CM, Peladeau-Pigeon M, Barbon CA, Guida BT, Namasivayam-MacDonald AM, Nascimento WV, et al. Reference Values for Healthy Swallowing Across the Range From Thin to Extremely Thick Liquids. J Speech Lang Hear Res. 2019 May;62(5):1338-63.

15 Côté C, Germain I, Dufresne T, Gagnon C. Comparison of two methods to categorize thickened liquids for dysphagia management in a clinical care setting context: the Bostwick consistometer and the IDDSI Flow Test. Are we talking about the same concept? J Texture Stud. 2019 Apr;50(2):95-103.

16 Payne C, Methven L, Fairfield C, Gosney M, Bell AE. Variability of starch-based thickened drinks for patients with dysphagia in the hospital setting. J Texture Stud. 2012;43(2):95-105.
17 Mertz Garcia J, Chambers E 4th, Cook K. Visualizing the consistency of thickened liquids with simple tools: implications for clinical practice. Am J Speech Lang Pathol. 2018 Feb;27(1):270-7.

18 Payne C, Methven L, Fairfield C, Bell A. Consistently inconsistent: commercially available starch-based dysphagia products. Dysphagia. 2011 Mar;26(1):27-33.

19 Glassburn DL, Deem JF. Thickener viscosity in dysphagia management: variability among speech-language pathologists. Dysphagia. 1998;13(4):218-22.

20 Goulding R, Bakheit AM. Evaluation of the benefits of monitoring fluid thickness in the dietary management of dysphagic stroke patients. Clin Rehabil. 2000 Apr;14(2):119-24.

21 Adeleye B, Rachal C. Comparison of the rheological properties of ready-to-serve and powdered instant food-thickened beverages at different temperatures for dysphagic patients. J Am Diet Assoc. 2007 Jul;107(7):1176-82.

22 Newman R, Vilardell N, Clavé P, Speyer R. Effect of bolus viscosity on the safety and efficacy of swallowing and the kinematics of the swallow response in patients with oropharyngeal dysphagia: White paper by the European Society for Swallowing Disorders (ESSD). Dysphagia. 2016 Apr;31(2):232-49.

23 Su M, Zheng G, Chen Y, Xie H, Han W, Yang $\mathrm{Q}$, et al. Clinical applications of IDDSI framework for texture recommendation for dysphagia patients. J Texture Stud. 2018 Feb;49(1):2-10.

$24 \mathrm{Kim}$ YH, Jeong GY, Yoo B. Comparative study of IDDSI flow test and line-spread test of thickened water prepared with different dysphagia thickeners. J Texture Stud. 2018 Dec;49(6):653-8.

25 Gatenby A. How are consistency, surface tension and viscosity different? CSC Scientific Company, Inc. 2014. Available from: https:// www.cscscientific.com/csc-scientific-blog/ how-are-consistency-surface-tension-andviscosity-different.

26 Milczarek RR, McCarthy KL. Relationship between the Bostwick measurement and fluid properties. J Texture Stud. 2006;37(6):640-54.

27 American Society for Testing and Materials International. ASTM F1080-93: Standard test method for determining the consistency of viscous liquids using a consistometer. West Conshohoken, ASTM: 2002.

28 International Dysphagia Diet Standardisation Initiative. Testing methods for use with the IDDSI framework. 2019. Available from: https://iddsi.org/IDDSI/media/images/Testing_Methods_IDDSI_Framework_Final_31_July2019.pdf.
29 Garcia JM, Chambers E 4th. Managing dysphagia through diet modifications. Am J Nurs. 2010 Nov;110(11):26-33.

30 Hadde EK, Chen J. Shear and extensional rheological characterization of thickened fluid for dysphagia management. J Food Eng. 2019;245:18-23.

31 Hadde EK, Nicholson TM, Cichero JA. Evaluation of thickened fluids used in dysphagia management using extensional rheology. Dysphagia. 2020 Apr;35(2):242-52.

32 Park JH, Kim HG, Oh BM, Lee MW, Hwang IK, Lee SU, et al. Comparison of different gum-based thickeners using a viscometer and line spread test: a preliminary study. Ann Rehabil Med. 2014 Feb;38(1):94-100.

33 Bourne M. Food texture and viscosity: Concept and measurement. 2nd ed. Cambridge: Academic Press; 2002.

34 Marcotte M, Hoshahili AR, Ramaswamy HS. Rheological properties of selected hydrocolloids as a function of concentration and temperature. Food Res Int. 2001;34(8):695-703.

35 Nestlé Health Science. Resource ${ }^{\circledR}$ Thicken$\mathrm{Up}^{\circledR}$. Available from: https://www.nestlehealthscience.co.uk/brands/resource-dysphagia/resource-thickenup-clear.

36 Nestlé Health Science. Resource ${ }^{\circledR}$ Thicken$\mathrm{Up}^{\circledR}$ Clear. Available from: https://www. nestlehealthscience.co.uk/brands/resourcedysphagia/resource-thickenup.

37 American Speech-Language-Hearing Association. International Dysphagia Diet Standardisation Initiative (IDDSI). Available from: https:// www.asha.org/SLP/healthcare/InternationalDysphagia-Diet-Standardisation-Initiative/.

38 Speech Pathology Australia. Modified foods and fluids terminologies. Available from: https:// www.speechpathologyaustralia.org.au/ SPAweb/Resources_for_the_Public/Modified Foods_and_Fluids_Terminology/SPAweb/Resources_for_Speech_Pathologists/Professional_Resources/Modified_Foods_and_Fluids Terminology.aspx ?hkey $=822 \mathrm{fd} 30 \mathrm{c}$ b7d4-45c3-9071-a20a7b38bb52.

39 British Dietetic Association. The BDA announces the adoption of the International Dysphagia Diet Standardisation Initiative (IDDSI) framework. 2017. Available from: https://www.bda.uk.com/resource/the-bdaannounces-adoption-of-the-internationaldysphagia-diet-standardisation-initiative-iddsi-framework.html.

40 International Dysphagia Diet Standardisation Initiative. Chinese (Hong Kong) translations of the IDDSI Framework and IDDSI Testing Methods are now available for peer review. 2020. Available from: https://twitter.com/iddsi_org/status/1245407913700519936. 